\title{
Cardiorespiratory Response to Exercise after the Fontan Procedure for Tricuspid Atresia ${ }^{1}$
}

\author{
GEORDIE P. GRANT, ${ }^{2}$ ANTHONY L. MANSELL, ${ }^{3}$ ROBERT P. GAROFANO, \\ CONSTANCE J. HAYES, FREDERICK O. BOWMAN, JR., AND WELTON M. GERSONY \\ Departments of Anesthesiology, Pediatrics, and Surgery, College of Physicians and Surgeons of Columbia \\ University, New York, New York 10032
}

\begin{abstract}
Noninvasive exercise testing was used to assess gas exchange in 13 patients age 6-25 yr who had undergone Fontan procedures for tricuspid atresia, five of whom had preexisting Glenn shunts. The results were compared to 28 age- and sex-matched controls. Oxygen saturation was measured by ear oximetry at rest and after exercise. Ventilation, oxygen consumption $\left(\dot{\mathrm{V}} \mathrm{O}_{2}\right)$, carbon dioxide production $\left(\mathrm{VCO}_{2}\right)$, and heart rate were measured during progressive exercise. The ventilatory equivalents for oxygen $\left(\dot{\mathrm{V}}_{\mathrm{E}} / \dot{\mathrm{V}} \mathrm{O}_{2}\right)$ and carbon dioxide $\left(\dot{\mathrm{V}}_{\mathrm{E}} / \mathrm{V} \mathrm{CO}_{2}\right)$, mixed expired $\mathrm{pCO}_{2}\left(\mathrm{P}_{\mathrm{E}} \mathrm{CO}_{2}\right)$ end-tidal $\mathrm{pCO}_{2}\left(\mathrm{P}_{\mathrm{ET}} \mathrm{CO}_{2}\right)$, and dead space to tidal volume ratio $\left(V_{\mathrm{D}} / \mathrm{V}_{\mathrm{T}}\right)$ were determined during steady state exercise on a cycle ergometer. Heart rate was higher for $\mathrm{VO}_{2}$ by $15 \%(p<0.02)$ and ventilation was higher for both $\mathrm{VO}_{2}$ (by $37 \%, p<0.001$ ) and $\dot{\mathrm{V}} \mathrm{CO}_{2}$ (by $27 \%, p<0.002)$ in the patients than the controls. Mean $\dot{\mathrm{V}}_{\mathrm{E}} / \dot{\mathrm{VO}}_{2}$ was $35.4 \pm 7.8$ (SD) compared to $25.8 \pm 3.1(p$ $<0.001)$ and mean $\dot{\mathrm{V}}_{\mathrm{E}} / \dot{\mathrm{V}} \mathrm{CO}_{2}$ was $41.7 \pm 9.0$ compared to $31.6 \pm 4.3(p<0.001)$. Mean $\mathrm{P}_{\mathrm{E}} \mathrm{CO}_{2}$ was $21.4 \pm 4.4$ torr with controls at $27.9 \pm 3.8(p<0.001)$ and mean $\mathrm{P}_{\mathrm{ET}} \mathrm{CO}_{2}$ was $33.0 \pm 5.3$ torr compared to $40.0 \pm 3.3(p<0.001)$. The patients had a mean oxygen saturation of $92 \pm 5 \%$ at rest and abnormal saturation after exercise $(87 \pm 9, p<$ 0.005). There were no differences in $\dot{\mathrm{V}}_{\mathrm{E}} / \dot{\mathrm{V}} \mathrm{O}_{2}, \dot{\mathrm{V}}_{\mathrm{E}} / \dot{\mathrm{V}} \mathrm{CO}_{2}$, $\mathrm{P}_{\mathrm{E}} \mathrm{CO}_{2}, \mathrm{P}_{\mathrm{ET}} \mathrm{CO}_{2}$, \% of $\mathrm{Hb}$ saturated with oxygen before and after exercise, or $V_{D} / V_{T}$ ratios between the five patients who had also undergone the Glenn operation and those who had not. Two patients who had right atrium to right pulmonary artery anastomoses demonstrated higher $\left(\mathrm{V}_{\mathrm{E}} /\right.$ $\dot{\mathrm{V}} \mathrm{O}_{2}$ and $\dot{\mathrm{V}}_{\mathrm{E}} / \mathrm{VCO}_{2}$ ratios, lower end-tidal and mixed expired $\mathrm{pCO}_{2}$, and lower $\%$ of $\mathrm{Hb}$ saturated with oxygen before and after exercise than the patients with right atrium to right ventricle anastomoses. Patients with tricuspid atresia who have undergone the Fontan operation show high heart rate for oxygen consumption, high ventilation for $\mathrm{O}_{2}$ consumption and $\mathrm{CO}_{2}$ production, low expired $\mathrm{CO}_{2}$ concentrations, and oxygen desaturation during exercise. The results indicate elevated physiological dead space and ventilation perfusion mismatch consistent with maldistribution of pulmonary blood flow in patients with Fontan physiology who have had either a right atrium to pulmonary artery or right atrium to right ventricle connection with or without a previous Glenn shunt. Longer follow-up of these patients
\end{abstract}

Received September 14, 1987; accepted February 25, 1988.

Correspondence and reprint requests Geordie P. Grant, M.D., Department of Anesthesiology, UMDNJ-NJ Medical School, 185 South Orange Avenue, Newark, NJ 07103-2757.

I Preliminary results were presented at the Society for Pediatric Research meeting in Washington, D.C. on May 7, 1985.

${ }^{2}$ Presently an Associate Professor of Clinical Anesthesiology at the University of Medicine and Dentistry, New Jersey Medical School, Newark, NJ.

${ }^{3}$ Presently an Associate Professor of Pediatrics and Director, Division of Pediatric Pulmonology, Brown University, Providence, RI. will be necessary to determine the late clinical implications of these findings. (Pediatr Res 24: 1-5, 1988)

Abbreviations

$\dot{\mathrm{V}}_{\mathrm{E}}$, minute ventilation

$\dot{\mathrm{V}} \mathrm{O}_{2}$, oxygen consumption

$\dot{\mathrm{V}} \mathrm{CO}_{2}$, carbon dioxide production

$\dot{\mathbf{V}}_{\mathrm{E}} / \dot{\mathbf{V}} \mathbf{O}_{2}$, ventilatory equivalent for oxygen

$\dot{\mathrm{V}}_{\mathrm{E}} / \dot{\mathrm{V}}_{\mathrm{CO}}$, ventilatory equivalent for carbon dioxide

$\mathrm{P}_{\mathrm{E}} \mathrm{CO}_{2}$, mixed expired partial pressure of carbon dioxide

$\mathrm{P}_{\mathrm{ET}} \mathrm{CO}_{2}$, end-tidal partial pressure of carbon dioxide

$V_{\mathrm{D}} / \mathrm{V}_{\mathrm{T}}$, dead space to tidal volume ratio

$\mathrm{SaO}_{2}$, percent of hemoglobin saturated with oxygen

FEV1, forced expiratory volume in $1 \mathrm{~s}$

A study by Cloutier et al. (1) showed maldistribution of pulmonary blood flow in two patients after the Fontan procedure due to low perfusion pressures. The Glenn shunt is associated with a similar hemodynamic picture (2-5) as well as long-term evidence of the development of pulmonary arteriovenous fistulae (6) in the lower lung lobes. Also, patients who have undergone the Fontan procedure have reduced exercise tolerance which may be associated with maldistribution of pulmonary blood flow (7-10).

As an index of maldistribution, physiologic dead space can be measured noninvasively from expired gases. The measurement becomes more accurate during steady state exercise, when large volumes of expired gas are appropriate for high metabolic rates. Using this method, our study was done to find whether maldistribution of pulmonary perfusion expected in patients who had undergone the Fontan procedure (type of procedure listed in Table 1) for tricuspid atresia is detectable by analysis of expired gas during exercise. In addition, we sought possible differences in degree of maldistribution associated with a preexisting Glenn shunt.

\section{METHODS}

Subjects. Studies were performed on 13 patients (six females, seven males) who were at least 2 yr post-Fontan procedure for tricuspid atresia. The age ranged from 6 to $25 \mathrm{yr}$. Eleven of the patients had right atrium to right ventricle anastomoses (nine valved conduits); two had right atrium to right pulmonary artery anastomoses. Five of the patients had also undergone a Glenn procedure; superior vena cava to right pulmonary artery shunt (Table 1). All but one patient were New York Heart Association class 1; patient 1 who was cyanotic at rest was class II. Nine of the patients were students at the time of the study and participated in regularly scheduled gym activities, with two limited to 
Table 1. Subjects

\begin{tabular}{|c|c|c|c|c|}
\hline & $\begin{array}{l}\text { Age at } \\
\text { Study }\end{array}$ & Operations & $\begin{array}{l}\text { Yr since } \\
\text { Fontan }\end{array}$ & $\begin{array}{l}\text { Yr since } \\
\text { Glenn }\end{array}$ \\
\hline \multicolumn{5}{|l|}{ Patients } \\
\hline 1 & 11 & Gln, ${ }^{*}$ RA-PA $\dagger$ & 6 & 10 \\
\hline 2 & 18 & $\begin{array}{l}\text { Gln, RA-RV: } \\
\text { valved conduit }\end{array}$ & 6 & 11 \\
\hline 3 & 19 & $\begin{array}{l}\text { Gln, RA-RV } \\
\text { valved conduit }\end{array}$ & 6 & 15 \\
\hline 4 & 19 & Gln, RA-RV & 9 & 18 \\
\hline 5 & 24 & $\begin{array}{l}\text { Gln, RA-PA } \\
\text { RA-RV }\end{array}$ & $\begin{array}{r}11 \\
3\end{array}$ & 23 \\
\hline 6 & 6 & RA-PA & 2 & \\
\hline 7 & 10 & $\begin{array}{l}\text { RA-RV, valved } \\
\text { conduit }\end{array}$ & 9 & \\
\hline 8 & 13 & $\begin{array}{l}\text { RA-RV, valved } \\
\text { conduit }\end{array}$ & 8 & \\
\hline 9 & 13 & $\begin{array}{c}\text { PA band, RA-RV } \\
\text { valved conduit }\end{array}$ & 4 & \\
\hline 10 & 19 & $\begin{array}{l}\text { RA-RV, valved } \\
\text { conduit }\end{array}$ & 8 & \\
\hline 11 & 21 & $\begin{array}{l}\text { RA-RV, valved } \\
\text { conduit }\end{array}$ & 7 & \\
\hline 12 & 24 & $\begin{array}{l}\text { Potts, RA-RV, } \\
\text { valved conduit }\end{array}$ & 4 & \\
\hline 13 & 25 & $\begin{array}{l}\text { RA-RV, valved } \\
\text { conduit }\end{array}$ & 4 & \\
\hline $\begin{array}{r}\text { Controls } \\
n=28\end{array}$ & $\begin{array}{c}15 \\
(7-27)\end{array}$ & & & \\
\hline
\end{tabular}

* Glenn shunt.

$\dagger$ Right atrium to pulmonary artery anastomosis.

$\ddagger$ Right atrium to right ventricle anastomosis.

noncontact sports. Nine of the patients underwent postoperative cardiac catheterization at rest. No patients had angiographic evidence of intracardiac right to left shunting. One patient had a tiny residual ventricular septal defect resulting in a small left to right shunt. Two patients, one the class II patient with a Glenn shunt and a right atrium to pulmonary artery anastomosis, and the second with a right atrium to right ventricle anastomosis with no valved conduit, had evidence of right to left shunting diagnosed as intrapulmonary. A third patient, who had a right atrium to pulmonary artery anastomosis, had significant bronchopulmonary collateral circulation. The mean cardiac index calculated in seven of the patients was $3.5 \pm 0.9 \mathrm{liter} / \mathrm{min} / \mathrm{m}^{2}$. The control group consisted of 28 healthy subjects, 11 females and 17 males, 7 to $27 \mathrm{yr}$ old (mean age $15 \mathrm{yr}$ ).

Exercise protocol. All studies were conducted on a Godart bicycle ergometer (no. 1333) in the upright position. An estimate of arterial oxygen saturation was made before and after each incremental exercise test using a Hewlett-Packard ear oximeter (HP-47201A). FEV1 was measured using a 7 L Collins waterfilled spirometer. Twelve electrocardiogram leads were placed for monitoring during exercise and for measurement of heart rate. The subject breathed through a Koegel two-way valve for measurement of mixed expired and end tidal gases.

Each subject first performed a progressive exercise test, pedalling at $0 \mathrm{~W}$ for 4 min with subsequent incremental increases in workload each minute by an amount determined by height as recommended by Godfrey et al. (11). The test was continued until a subject was unable to pedal at $60 \mathrm{rpm}$ for 1 full min at the given workload. The subject then rested until the heart rate returned to baseline.

A steady-state exercise test was then performed at $0 \mathrm{~W}$ and power outputs approximately 25 and $45 \%$ of the maximum workload achieved in the incremental exercise test. Steady state was defined as a constant mixed expired gas composition after at least $4 \mathrm{~min}$ of exercise.

For steady-state and incremental exercise tests inspired ventilation was measured with a dry-gas meter (Parkinson-Cowan, CD 4). Expired gas was routed through low-resistance tubing to a Jaeger mixing chamber (N8094). Mixed expired gas was sampled from the mixing chamber after drying with Drierite crystals (CaSO4, 8 mesh) with a Beckman LB2 carbon dioxide analyzer and a Beckman OM-14 oxygen analyzer, using a heated sampling tube $\left(37^{\circ} \mathrm{C}\right)$. End-tidal gases were sampled during steady-state exercise immediately distal to the mouthpiece and were not dried. The Beckman analyzers were calibrated using a range of gases containing 4 to $7 \% \mathrm{CO}_{2}$. The calibration gases were analyzed against a precision calibration gas, typically containing $5 \% \mathrm{CO}_{2}$, $16 \% \mathrm{O}_{2}$. The precision gas, primary standard, was analyzed by the gravimetric method, referable to the National Bureau of Standards. Measurements of heart rate, inspired ventilation, carbon dioxide concentrations, and oxygen concentrations were recorded on a Hewlett-Packard strip recorder (7758B). A 12-lead electrocardiogram was recorded on a Quinton Status 1000 recorder every minute during incremental exercise and during each stage of steady state exercise.

Calculations. $\dot{\mathrm{V}} \mathrm{CO}_{2}, \dot{\mathrm{V}} \mathrm{O}_{2}, \dot{\mathrm{V}}_{\mathrm{E}} / \dot{\mathrm{VO}}_{2}$, and $\dot{\mathrm{V}}_{\mathrm{E}} / \dot{\mathrm{V} C O} \mathrm{O}_{2}$ were calculated using standard equations (12); inspired ventilation was converted to expired ventilation by applying the nitrogen correction (Haldane transformation). Maximum voluntary ventilation was estimated by multiplying the FEV 1 by $35(12) . \mathrm{V}_{\mathrm{D}} / \mathrm{V}_{\mathrm{T}}$ ratios were calculated using the Bohr equation, with arterial $\mathrm{pCO}_{2}$ estimated from end-tidal $\mathrm{pCO}_{2}$ (13).

Statistical analysis. Covariant analysis was used to compare patients to controls regarding $\dot{\mathrm{V}}_{\mathrm{E}}$ with respect to $\dot{\mathrm{VO}}_{2}$ and $\dot{\mathrm{V}}_{\mathrm{CO}}$ and heart rate with respect to $\dot{\mathrm{VO}}_{2}$ (14). The unpaired Student's two-tailed $t$ test was used to compare peak oxygen consumption, $\dot{\mathrm{V}}_{\mathrm{E}} / \dot{\mathrm{VO}}_{2}$ and $\dot{\mathrm{V}}_{\mathrm{E}} / \dot{\mathrm{V}} \mathrm{CO}_{2}, \mathrm{P}_{\mathrm{E}} \mathrm{CO}_{2}, \mathrm{P}_{\mathrm{ET}} \mathrm{CO}_{2}$, and $\mathrm{V}_{\mathrm{D}} / \mathrm{V}_{\mathrm{T}}$. The paired Student's two-tailed $t$ test was used to compare $\mathrm{SaO}_{2}$ before and after exercise. SD was used as the index of dispersion.

\section{RESULTS}

The maximum ventilation achieved during incremental exercise divided by the predicted maximum voluntary ventilation was $55 \pm 21 \%$ for the patients and $50 \pm 13 \%$ for the controls. This difference was not significant. The peak oxygen consumption achieved during incremental exercise was significantly lower for the patients $(23.3 \pm 6.1 \mathrm{ml} / \mathrm{min} / \mathrm{kg})$ compared to the controls $(37.7 \pm 9.0)(p<0.001)$. There was no significant difference in the maximum heart rate achieved by the patients $(164 \pm 16$ $\mathrm{bpm})$ and the controls $(175 \pm 16)$. The ventilatory equivalents for oxygen and carbon dioxide were higher in the patients at peak oxygen consumption $(p<0.001$ and $p<0.005$, respectively) (Table 2). FEV1 divided by vital capacity was $92 \pm 5 \%$.

Ventilation. $\dot{\mathrm{V}}_{\mathrm{E}}$ was higher during incremental exercise for both $\dot{\mathrm{V}} \mathrm{O}_{2}$ and $\dot{\mathrm{V}} \mathrm{CO}_{2}$ in the patients than the control group. At a $\dot{\mathrm{V}} \mathrm{O}_{2}$ of $0.7 \mathrm{liter} / \mathrm{min}, \dot{\mathrm{V}}_{\mathrm{E}}$ was $37 \%$ higher than in the controls $(p<0.001)$ (Fig. 1). At a $\dot{\mathrm{V} C O}{ }_{2}$ of 0.7 liter/min, $\dot{\mathrm{V}}_{\mathrm{E}}$ was $27 \%$ higher for the patients $(p<0.002)$.

During steady state exercise, the $\dot{\mathrm{V}}_{\mathrm{E}} / \mathrm{V}_{2}$ were higher in the patients than in the controls $(35.4 \pm 7.8$ versus $25.8 \pm 3.1)(p<$

Table 2. Exercise data at peak $\dot{\mathrm{V}} \mathrm{O}_{2}$

\begin{tabular}{lccc}
\hline & \multicolumn{1}{c}{ Fontan } & Controls & Significance \\
\hline$\dot{\mathrm{VO}}_{2}(\mathrm{ml} / \mathrm{kg} / \mathrm{min})$ & $23.3 \pm 6.1^{*}$ & $37.8 \pm 9.0$ & $p<0.001$ \\
Respiratory exchange & $1.02 \pm .16$ & $1.01 \pm .08$ & $\mathrm{NS}$ \\
$\quad$ ratio & & & \\
$\mathrm{Heart} \mathrm{rate}$ & $163 \pm 15$ & $174 \pm 17$ & $\mathrm{NS}$ \\
$\dot{\mathrm{V}}_{\mathrm{E}}$ & $39.8 \pm 9.7$ & $53.8 \pm 22.5$ & $p<0.05$ \\
$\dot{\mathrm{V}}_{\mathrm{E}} / \dot{\mathrm{VO}}_{2}$ & $38.7 \pm 11.2$ & $28.2 \pm 3.9$ & $p<0.001$ \\
$\dot{\mathrm{V}}_{\mathrm{E}} / \dot{\mathrm{VCO}}_{2}$ & $38.0 \pm 11.5$ & $28.1 \pm 4.0$ & $p<0.005$ \\
\hline
\end{tabular}

* $\mathrm{SD}$ is used as the index of dispersion. 
0.001). The $\dot{\mathrm{V}}_{\mathrm{E}} / \dot{\mathrm{VCO}}_{2}$ were also higher in the patients $(41.7 \pm$ 9.0 versus $31.6 \pm 4.3)(p<0.001)$. Both $\mathrm{P}_{\mathrm{E}} \mathrm{CO}_{2}$ and $\mathrm{P}_{\mathrm{ET}} \mathrm{CO}_{2}$ were decreased for the patients $(p<0.001)$ (Fig. 2). $V_{\mathrm{D}} / \mathrm{V}_{\mathrm{T}}$ ratios (Fig. 2) were increased for the patients $(0.31 \pm 0.05$ versus $0.25 \pm$ $0.05)(p<0.005)$.

Arterial saturation. Individual measurements of $\mathrm{Hb}$ oxygen saturation by ear oximetry in the sitting position for the 13 patients before and immediately after incremental exercise are illustrated in Figure 3. The mean saturation before exercise was $92 \pm 5 \%$ and after exercise was $87 \pm 9 \%(p<0.005)$. The values were abnormally low $(<95 \%)$ in eight of the patients before exercise and 11 of the patients desaturated during exercise. The mean of 28 controls was $96 \pm 1 \%$ before exercise. The mean of eight controls retested after exercise was $96 \pm 2 \%$.

Heart rate, electrocardiographic $S T$ segment and $T$ wave

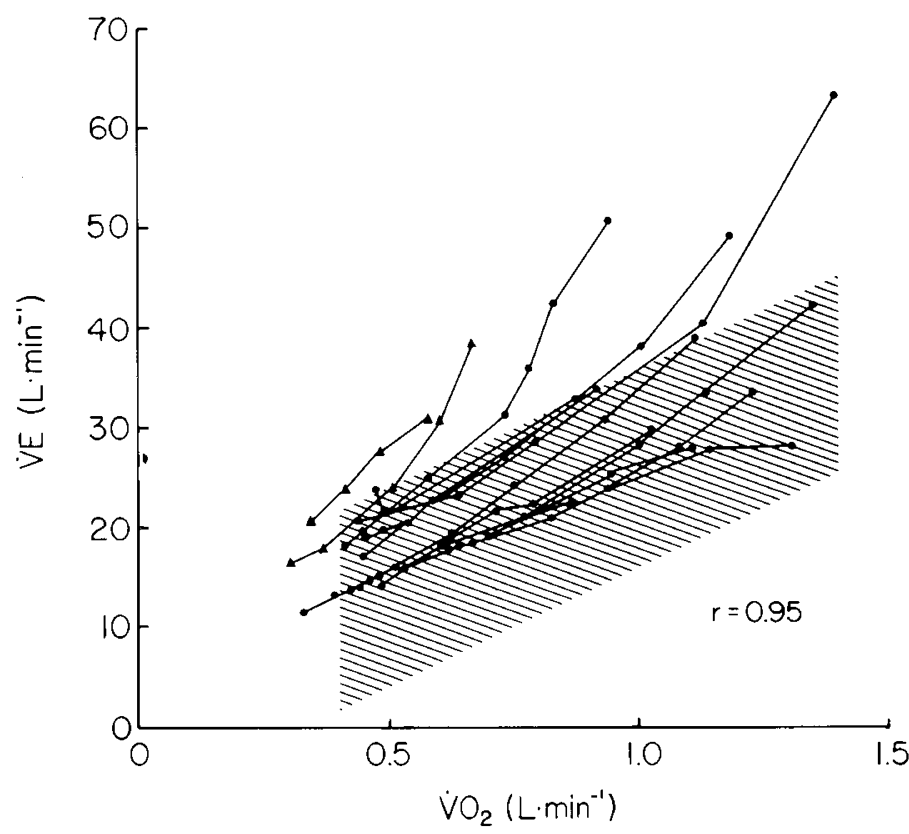

Fig. 1. Ventilation (liter/min) as a function of $\mathrm{VO}_{2}$ (liter/min) during incremental exercise. The shaded area represents the regression line \pm $95 \%$ confidence limits from 20 controls $(r=0.95)$. Each triangle represents one work load in a patient with a right atrium to pulmonary artery anastomosis. Each closed circle represents one work load in a patient with a right atrium to right ventricle anastomosis.

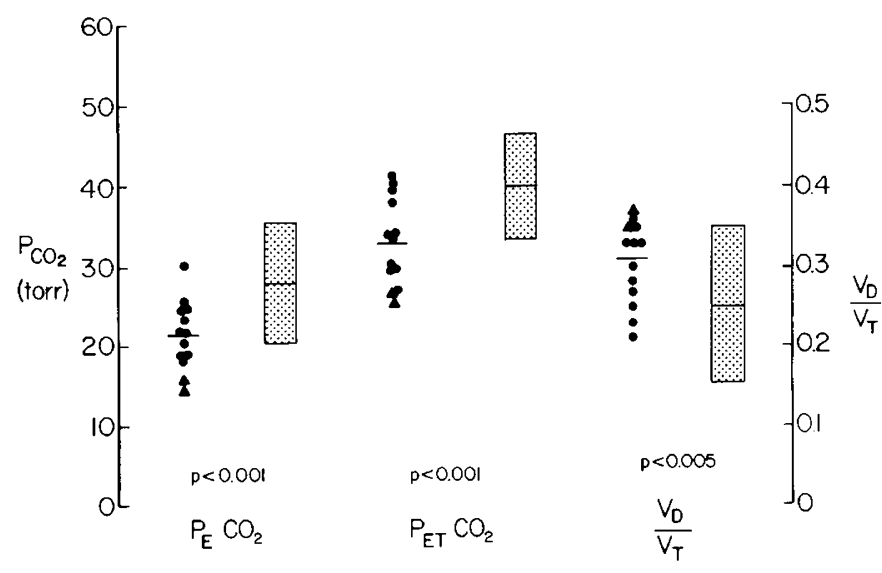

Fig. 2. $\mathrm{P}_{\mathrm{E}} \mathrm{CO}_{2}, \mathrm{P}_{\mathrm{ET}} \mathrm{CO}_{2}$, and $\mathrm{V}_{\mathrm{D}} / \mathrm{V}_{\mathrm{T}}$ during steady state exercise. The shaded areas represent the mean $\pm 2 \mathrm{SD}$ obtained from 20 controls. Each triangle represents the mean $\mathrm{pCO}_{2}$ or $\mathrm{V}_{\mathrm{D}} / \mathrm{V}_{\mathrm{T}}$ of a patient with a right atrium to pulmonary artery anastomosis. Each closed circle represents the mean of a patient with a right atrium to right ventricle anastomosis.

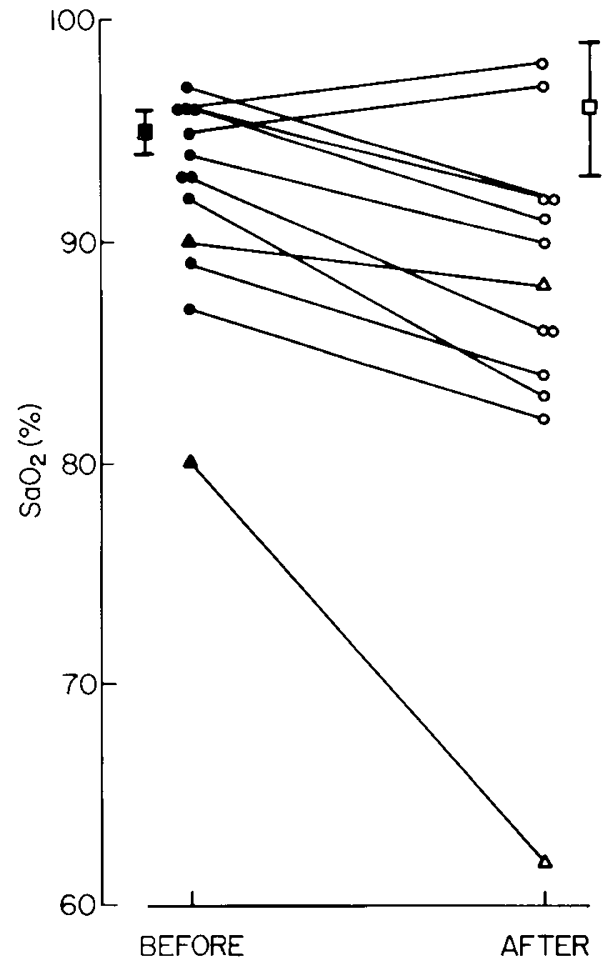

Fig. 3. $\mathrm{SaO}_{2}$ measured by ear oximetry before and immediately after incremental exercise. The closed square and bars represent the mean value $\pm 2 \mathrm{SD}$ obtained before exercise and open square and bars after exercise from eight controls. Each closed triangle represents the $\mathrm{SaO}_{2}$ of a patient with a right atrium to pulmonary artery anastomosis before exercise and each open triangle after exercise. Each closed circle represents the $\mathrm{SaO}_{2}$ of a patient with a right atrium to right ventricle anastomosis before exercise and each open circle after exercise.

changes, and arrhythmia. One patient developed a significant supraventricular tachycardia during progressive exercise and thus the heart rate data from this patient were not included in the analysis. Two patients developed mild atrial or ventricular ectopy during recovery. Seven of the patients developed either ST segment depression, diffuse ST or $\mathrm{T}$ wave changes or $\mathrm{T}$ wave inversions during exercise that resolved during recovery. The mean heart rate for the patients at $16 \mathrm{ml} / \mathrm{min} / \mathrm{kg}$ was $15 \%$ higher than the controls $(135 \pm 24 \mathrm{bpm}$ versus $117 \pm 15)(p<0.02)$ (Fig. 4).

The two patients who had right atrium to right pulmonary artery anastomoses demonstrated higher $\dot{\mathrm{V}}_{\mathrm{E}} / \dot{\mathrm{V}}_{2}$ ratios, lower end-tidal and mixed expired $\mathrm{pCO}_{2}$ values and lower $\mathrm{SaO}_{2}$ values before and after exercise than the patients with right atrium to right ventricle anastomoses. (Figs. 1-3).

There were no significant differences in $\dot{\mathrm{V}}_{\mathrm{E}} / \dot{\mathrm{VO}}_{2}, \dot{\mathrm{V}}_{\mathrm{E}} / \dot{\mathrm{V} C O}_{2}$, $\mathrm{P}_{\mathrm{E}} \mathrm{CO}_{2}, \mathrm{P}_{\mathrm{ET}} \mathrm{CO}_{2}, \mathrm{~S}_{\mathrm{a}} \mathrm{O}_{2}$ before and after exercise, or $\mathrm{V}_{\mathrm{D}} / \mathrm{V}_{\mathrm{T}}$ ratios between patients who had also undergone the Glenn operation and those who had not (Table 3).

\section{DISCUSSION}

Patients who have undergone the Fontan procedure with or without a previous Glenn shunt for tricuspid atresia have a low pulsatile pulmonary blood flow. Perfusion studies in patients with Glenn shunts alone have shown this is associated with a maldistribution of pulmonary blood flow manifested by an increased distribution to the lower lung lobes (2-5). In addition long term follow-up after Glenn shunts has revealed the development of pulmonary arteriovenous fistulae in the lower lobes (6). In our study analysis of expired gas during exercise was used to measure the elevated physiological dead space predicted by 
the suboptimal pulmonary blood flow and maldistribution of perfusion shown in the previous studies.

Under normal conditions pulmonary blood flow is decreased to the upper lung lobes relative to the lower lobes. This is thought to partially explain the small amount of physiological dead space and venous admixture found in normal subjects. When these conditions are exaggerated by suboptimal pulmonary blood flow, areas of lung are ventilated but not perfused and no evolution of carbon dioxide into alveolar gas occurs. This phenomenon is reflected by a decrease in the concentration of carbon dioxide in mixed expired and end-tidal gas measurements. The magnitude of this effect is expressed by the Bohr equation. Our results showed an increase in dead space during exercise using the Bohr equation. However, since we used end-tidal $\mathrm{pCO}_{2}$ which underestimates arterial $\mathrm{pCO}_{2}$, the dead space was underestimated. Therefore, our approximation is on the conservative side.

In addition to low pulmonary blood flow, high physiological dead space can also be caused by an abnormal distribution of ventilation. This possibility is excluded by normal ventilation

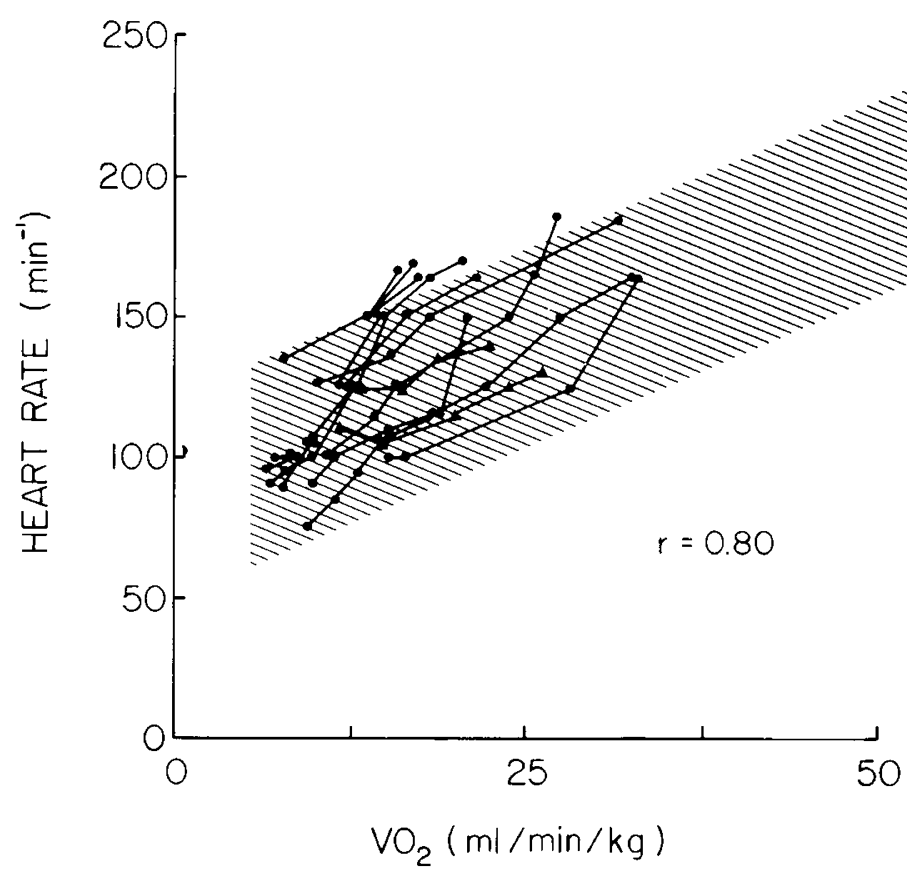

Fig. 4. Heart rate as a function of $\mathrm{VO}_{2}$ during incremental exercise obtained from 12 of the patients. The shaded area represents the regression line $\pm 95 \%$ confidence limits $(r=0.80)$ from 20 controls. Each triangle represents one work load in a patient with a right atrium to pulmonary artery anastomosis. Each closed circle represents one work load in a patient with a right atrium to right ventricle anastomosis. scans found in previous studies (1) as well as the normal distribution of ventilation seen in the alveolar plateaus in our study.

Maldistribution of pulmonary blood flow also explains the low oxygen saturation found in our patients both before and after exercise. At a constant total pulmonary blood flow, lung regions with high ventilation/perfusion ratios must be associated with areas of low ventilation/perfusion ratios. These low ventilation/ perfusion ratio areas lead to venous admixture. How these areas may lead to the development of arteriovenous fistulae is unknown. An alternative explanation for the hypoxemia would be intracardiac shunting. However, none of the patients studied had angiographic evidence of right to left intracardiac shunt during cardiac catheterization.

Maldistribution of pulmonary blood flow is also consistent with the decreased exercise performance in our patients. This was manifested by a low peak oxygen consumption with a maximum heart rate that was similar to controls. At submaximal work loads, heart rate was elevated relative to oxygen consumption. Although cardiac output was normal in seven of the patients at rest, this implies a decrease in stroke volume during exercise. Other investigators have measured cardiac output and also estimated a low stroke volume during exercise $(7,8)$. A decrease in right heart output could contribute to the decreased pulmonary blood flow to the upper lung lobes leading ultimately to desaturation. Hypoxemia is known to increase the oxygen deficit and decrease the anaerobic threshold and the maximum oxygen consumption achieved during exercise (15-17).

We have shown that analysis of expired gas during exercise can be used to quantify high physiological dead space associated with maldistribution of pulmonary blood flow after cardiac surgery. We have also shown that these abnormalities occurred whether or not the patients had a Glenn shunt before the Fontan operation. Furthermore, the majority of the patients in this study had a right atrium to right ventricle operation described by Bowman et al. (18). Whereas one study showed that this operation improved pulsatile blood flow compared to the standard right atrium to pulmonary artery anastomosis (19), a later study showed that there was no difference (20). The two patients with right atrium to pulmonary artery anastomoses in this study had more severe ventilatory abnormalities. Although this may suggest that the pulmonary blood flow in the patients with right atrium to right ventricle anastomoses may be improved, there were too few patients to draw any general conclusions.

Despite an abnormal cardiorespiratory response to exercise, all the patients were active and clinically well. Long-term followup of these patients will be necessary to determine the clinical implications of these findings and the progression of the abnormalities with time.

\section{REFERENCES}

1. Cloutier A, Ash JM, Smallhorn JF, Williams WG, Trusler GA, Rowe RD, Rabinovitch M 1985 Abnormal distribution of pulmonary blood flow after the Glenn shunt or Fontan procedure: risk of development of arteriovenous fistulae. Circulation 72:471-479

Table 3. Comparison of patients with and without previous Glenn shunts

\begin{tabular}{|c|c|c|c|c|c|c|}
\hline Patients & $\dot{\mathrm{V}}_{\mathrm{E}} / \dot{\mathrm{VO}}_{2}$ & $\dot{\mathrm{V}}_{\mathrm{E}} / \dot{\mathrm{VCO}}_{2}$ & $\begin{array}{c}\mathrm{P}_{\mathrm{E}} \mathrm{CO}_{2} \\
\text { (torr) }\end{array}$ & $\begin{array}{c}\mathrm{P}_{\mathrm{ETCO}} \mathrm{CO}_{2} \\
\text { (torr) }\end{array}$ & $\begin{array}{l}\mathrm{S}_{\mathrm{a}} \mathrm{O}_{2} \\
\text { (pre) }\end{array}$ & $\begin{array}{c}\mathrm{S}_{2} \mathrm{O}_{2} \\
\text { (post) } \\
\end{array}$ \\
\hline $\begin{array}{l}\text { Glenn* } \\
\quad(n=5)\end{array}$ & $34.3 \pm 6.9 \dagger$ & $42.0 \pm 7.9$ & $21.2 \pm 3.8$ & $32.2 \pm 5.3$ & $90 \pm 6$ & $82 \pm 13$ \\
\hline $\begin{array}{l}\text { No Glenn } \\
\quad(n=8)\end{array}$ & $35.1 \pm 8.0$ & $40.3 \pm 8.6$ & $22.6 \pm 4.9$ & $34.2 \pm 5.3$ & $94 \pm 3$ & $90 \pm 4$ \\
\hline Controls & $25.8 \pm 3.1 \ddagger$ & $31.6 \pm 4.3$ & $27.9 \pm 3.8$ & $40.0 \pm 3.3$ & $96 \pm 1 \S$ & $96 \pm 2 \|$ \\
\hline
\end{tabular}

* Differences between Glenn and no Glenn patients were not significant.

$\dagger \mathrm{SD}$ is used as the index of dispersion.

$\ddagger \dot{\mathrm{V}}_{\mathrm{E}} / \dot{\mathrm{VO}}_{2}, \dot{\mathrm{V}}_{\mathrm{E}} / \mathrm{V} \mathrm{CO}_{2}, \mathrm{P}_{\mathrm{E}} \mathrm{CO}_{2}$, and $\mathrm{P}_{\mathrm{ET}} \mathrm{CO}_{2}$ were obtained from 20 controls.

$\S$ Preexercise $\mathrm{SaO}_{2}$ values were obtained from 28 controls.

\| Postexercise $\mathrm{SaO}_{2}$ values were obtained from eight controls. 
2. Samanek M, Oppelt A, Kasalicky J, Voriskova M 1969 Distribution of pulmonary blood flow after cavopulmonary anastomosis (Glenn operation). $\mathrm{Br}$ Heart J 31:511-516

3. Laks H, Mudd JG, Standeven JW, Fagan L, Willman VL 1977 Long-term effect of the superior vena cava-pulmonary artery anastomosis on pulmonary blood flow. J Thorac Cardiovasc Surg 74:253-259

4. Boruchow IB, Swenson EW, Elliott LP, Bartley TD, Wheat MW, Schiebler GL 1970 Study of the mechanisms of shunt failure after superior vena cava-right pulmonary artery anastomosis. J Thorac Cardiovasc Surg 60:531-539

5. Pennington GD, Nouri S, Ho J, Secker-Walker R, Patel B, Sivakoff M, Willman VL 1981 Glenn shunt: long-term results and current role in congenital heart operations. Ann Thorac Surg 31:532-539

6. McFaul RC, Tajik AJ, Mair DD, Danielson GK, Seward JB 1977 Development of pulmonary arteriovenous shunt after superior vena cava-right pulmonary artery (Glenn) anastomosis. Circulation 55:212-216

7. Schachar GB, Fuhrman BP, Wang Y, Lucas RV, Lock JE 1982 Rest and exercise hemodynamics after the Fontan procedure. Circulation 65:10431048

8. Driscoll DJ, Danielson GK, Puga FJ, Schaff HV, Heise CT, Staats BA 1986 Exercise tolerance and cardiorespiratory to exercise after the Fontan operation for tricuspid atresia or functional single ventricle. J Am Coll Cardiol 7:1087-1094

9. Peterson RJ, Franch RH, Fajman WA, Jennings JG, Jones RH 1984 Noninvasive determination of exercise cardiac function following Fontan operation. J Thorac Cardiovasc Surg 88:263-274

10. Laks H, Milliken JC, Perloff JK, Hellenbrand WE, George BL, Chin A, Di
Sessa TG, Williams RG 1984 Experience with the Fontan procedure. J Thorac Cardiovasc Surg 88:939-951

11. Godfrey S, Davies CTM, Wozniak E, Barnes CA 1971 Cardiorespiratory response to exercise in normal children. Clin Sci 40:419-431

12. Jones NL, Campbell EJM 1982 Clinical Exercise Testing. WB Saunders Co, Philadelphia

13. Jones NL, Robertson DG, Kane JW 1979 Difference between end-tidal and arterial pCO2 in exercise. J Appl Physiol 47:954-960

14. Zar JH 1974 Comparing simple linear regression equations. In: Biostatistical Analysis. Prentice-Hall, Inc., Englewood Cliffs, NJ, pp 228-231

15. Linnarsson D, Karlsson J, Fagraeus L, Saltin B 1974 Muscle metabolites and oxygen deficit with exercise and hypoxia and hyperoxia. J Appl Physiol 36:399-402

16. Wasserman K, Whipp BJ, Koyal SN, Beaver WL 1973 Anaerobic threshold and respiratory gas exchange during exercise. J Appl Physiol 35:236-243

17. Hughes RL, Clode M, Edwards RHT, Goodwin TJ, Jones NL 1968 Effect of inspired $\mathrm{O} 2$ on cardiopulmonary and metabolic responses to exercise in man. J Appl Physiol 24:336-347

18. Bowman FO, Malm JR, Hayes CJ, Gersony WM 1978 Physiological approach to surgery for tricuspid atresia. Circulation 58(suppl 1):1-83

19. Bierman FZ, Bowman FO, Malm FR, Gersony WM 1983 Gated pulsed doppler assessment of pulmonary artery blood flow after Fontan operation. Circulation 68(suppl III):111-54(abstr)

20. DiSessa TG, Child JS, Perloff JK, Wu L, Williams RG, Laks H, Friedman WF 1984 Systemic venous and pulmonary arterial flow patterns after Fontan's procedure for tricuspid atresia or single ventricle. Circulation 70:898-902

\section{Announcement Research Proposal Competition}

Research proposals that can lead to a Ph.D. dissertation are invited from doctoral candidates on the "Relationship of Diet and Environmental Contaminants to Disordered Behavior." Creative and innovative ideas are encouraged. A packet of information on the subject plus Guidelines for Submittal is available upon request to the Wacker Foundation, 10848 Strait Lane, Dallas, TX 75229.

Submittal deadline is December 15,1988 . Winning entries will be determined by a panel of eminent scientists and will receive favorable consideration for funding. First place prize $\$ 2,500$, second place, $\$ 1,500$, and third place, \$500. Winners will be announced in February 1989. 